\title{
Are Online Gamblers More At Risk Than Offline Gamblers?
}

\author{
Sylvia Kairouz, Ph.D., ${ }^{1,2}$ Catherine Paradis, Ph.D.,, ${ }^{2,3}$ and Louise Nadeau, Ph.D. ${ }^{2,4}$
}

\begin{abstract}
Objectives: To characterize and compare sociodemographic profiles, game-play patterns, and level of addictive behaviors among adults who gamble online and those who do not, and to examine if, at the population level, online gambling is associated with more risky behaviors than offline gambling. Methods: Respondents were 8,456 offline gamblers and 111 online gamblers who participated in a population-based survey conducted in the province of Québec, in 2009. The study sample is representative of adult general population. Results: There is an unequal distribution of online gambling in the population. A disproportionate number of men, young people, and students say they participate in online gambling. Poker players are overrepresented among online gamblers and gambling behaviors tend to be more excessive on the Internet. Compared with offline gamblers, online gamblers report more co-occurring risky behaviors, namely alcohol and cannabis use. Conclusion: Those who gamble online appear to be more at risk for gambling-related problems, but the present findings alone cannot be used as evidence for that conclusion. Future research designs could combine longitudinal data collection and multilevel analyses to provide more insight into the causal mechanisms associated with online gambling.
\end{abstract}

\section{Introduction}

$\mathbf{T}$ HROUGH PRIVATE INTERNET access and mobile technology, online gambling has become readily accessible. The gambling field has thus seen dramatic changes over recent years. The number of gambling websites has grown from about 15 in 1995 to 2,358 in 2010. Global Internet gambling revenues have increased from $\$ 3$ billion in 2000 to $\$ 24$ billion in $2010 .^{1}$

In this context, many worry about the possible effects of this growth on public health. In Québec, when the Crown corporation announced its decision to set up a gambling website in 2010, public health directors from across the province openly expressed concerns that those who gamble online could be more prone to an array of gambling-related problems. ${ }^{2}$

Theoretical research undertaken by Griffiths ${ }^{3-5}$ over the last decade has shed light on how the Internet in itself can be addictive and how online gambling can increase the potential for other gambling-related problems. Empirical studies have drawn similar conclusions. For example, using a self-selected sample of 1,920 American, Canadian, and international Internet gamblers, Woods and Williams ${ }^{6}$ found that, compared with offline gamblers, Internet gamblers were more likely to have a higher score on the Canadian Problem Gambling In- dex (CPGI). In their study, 20.1 percent of Internet gamblers were classified as problem gamblers.

Only a few empirical studies have specifically compared online and offline gamblers. An analysis of the British Gambling Prevalence Survey showed that online players were more likely to positively score on the DSM-IV pathological gambling criteria. Online gamblers were also more likely to be male, young, single, educated and working in managerial or professional occupations than offline players. ${ }^{7}$ In a clinical sample, Ladd and Petry ${ }^{8}$ found that online gamblers were more likely to have a higher score on the South Oaks Gambling Screen, more likely to be young and more likely to be non-Caucasian than offline gamblers. Using an opportunity sample of 38 participants, Cole et al. ${ }^{9}$ observed that those who gambled on online roulette placed more chips per bet and made riskier bets than those who gambled on roulette offline.

Thus, empirical studies appear to support the idea that online gamblers are more at risk than their land-based counterparts. However, the majority of these findings are based on convenience samples that make it impossible to assess the extent to which they are representative of all online gamblers. Therefore, from an epidemiological perspective, very little is known about the characteristics of online gamblers compared to their offline counterparts.

\footnotetext{
${ }^{1}$ Department of Sociology and Anthropology, Concordia University, Montréal, Canada.

${ }^{2}$ Lifestyle and Addiction Research Lab, Concordia University, Montréal, Canada.

${ }^{3}$ Department of Political Studies, Bishop's University, Lennoxville, Canada.

${ }^{4}$ Department of Psychology, Université de Montréal, Montréal, Canada.
} 
This article examines whether, at the population level, those who gamble online are more at risk than those who gamble offline. The key objectives are to characterize and compare the sociodemographic profiles, game-play patterns, and level of addictive behaviors for adults who gamble online and offline in a representative, population-based sample of Québec adults.

\section{Methods}

\section{Sample}

This study used data from the 2009 Québec gambling survey (ENHJEU-QUÉBEC, 2009), which aimed to describe gambling patterns, gambling problems, and associated substance use behaviors in the Québec population. The survey targeted the population aged 18 and over, living in private dwellings; it excluded those individuals living on Indian Reserves or Crown lands, in certain remote regions, or in institutions. A two-stage sampling design was used, in which the administrative regions of Québec defined the first stratum. Within each stratum, we selected a number of dwellings proportionate to the square root of the population effect. At the second stage, one individual was selected in each selected dwelling. The overall weighted response rate was 54.4 percent and ranged between 41.3 percent and 60.5 percent across regions. For this study, only individuals who reported having participated in any of the 12 listed gambling activities at least once during the last 12 months were considered. The final sample was composed of 8,456 offline gamblers and 111 online gamblers.

\section{Measures}

Game-play patterns. Current gamblers reported their gambling frequency in the past year. They were asked to

Table 1. Comparison of Offline and Online Gamblers on Major Sociodemographic Characteristics

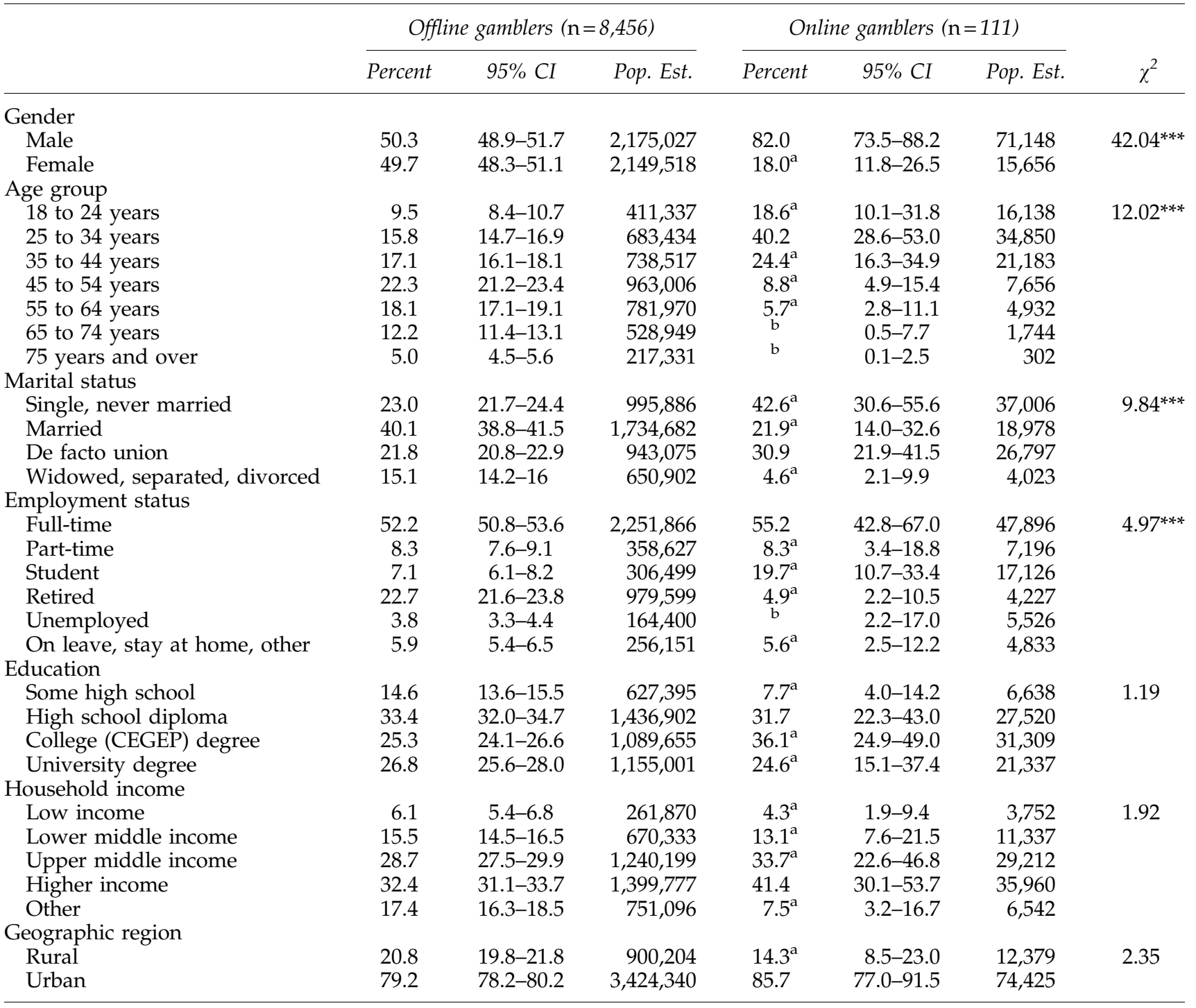

anterpret with caution.

${ }^{\mathrm{b}}$ Result nonpublishable.

${ }^{*} p \leq 0.05 ;{ }^{* *} p \leq 0.01 ;{ }^{* * *} p \leq 0.001$.

$\mathrm{CI}$, confidence interval; Pop. Est., population estimates. 
estimate the number of times they gambled weekly, monthly, or yearly. The time frame was determined by the respondent's spontaneous preference. The total number of times was summed across all activities and reported on a yearly basis. Afterward, scores were recoded into four categories ("less than monthly," "monthly but not weekly," "weekly but not daily," "daily and more"). Current gamblers also reported their spending either per occasion or on a weekly, monthly, or yearly basis. The total yearly spending was calculated by summing reported spending across all activities. They were asked to estimate the time they spend gambling on a typical occasion for each reported activity and total yearly time spent on gambling was calculated by summing the typical gambling time per occasion across all activities. To assess the severity of gambling problems, we used the overall score on the Problem Gambling Severity Index (PGSI), a modified version of the CPGI. ${ }^{10}$ The PGSI consists of nine items with answers reported on a 4 -point scale $(1=$ "Never"; $2=$ "Sometimes"; $3=$ "Most of the time"; $4=$ "Almost always"). Respondents were categorized as (a) nonproblem gamblers (score $=0$ on the PGSI); (b) low-risk gamblers (score = 1 or 2); (c) moderaterisk gamblers (score $=3$ to 7 ); or (d) problem gamblers (score $=8$ and above).
Other addictive behaviors. Respondents were asked about past-year frequency of alcohol consumption and problematic drinking using the Alcohol Use Diagnostic Identification Test (AUDIT). ${ }^{11,12}$ The AUDIT scores were recoded into three categories ( 0 to 7 = "nonproblem drinkers", 8 to $10=$ "problem drinkers", 11 and over $=$ "probable dependent drinkers"). We also measured the frequency of past-year cannabis use and past-year smoking.

Demographics. Respondents were differentiated according to gender, age, marital status, level of education, employment status, household income (as measured by income adequacy), and geographic region.

\section{Statistical analysis}

We used $\chi^{2}$ tests to assess associations between forms of gambling (online/offline) and demographic characteristics, game-play patterns, and prevalence of addictive behaviors. All estimates were weighted to represent the adult household population and were standardized by age, gender, and marital status to the 2006 Census population using the direct method. To account for the complex survey design, STATA

Table 2. Comparison of Offline and Online Gamblers on Game-Play Patterns

\begin{tabular}{|c|c|c|c|c|c|c|c|}
\hline & \multicolumn{3}{|c|}{ Offline gamblers $(\mathrm{n}=8,456)$} & \multicolumn{3}{|c|}{ Online gamblers $(\mathrm{n}=111)$} & \multirow[b]{2}{*}{$\chi^{2}$} \\
\hline & Percent & $95 \% C I$ & Pop. Est. & Percent & $95 \% C I$ & Pop. Est. & \\
\hline \multicolumn{8}{|l|}{ Gambling activities } \\
\hline Lottery $^{\mathrm{a}}$ & 92.9 & $92.0-93.8$ & $4,018,502$ & 77.0 & $64.2-86.2$ & 66,802 & $20.45^{* * *}$ \\
\hline Bingo & 6.5 & $5.8-7.2$ & 279,435 & $6.9^{\mathrm{b}}$ & $3.1-14.4$ & 5,951 & 0.02 \\
\hline Slot machines ${ }^{a}$ & 14.1 & $13.1-15.1$ & 607,469 & $31.0^{\mathrm{b}}$ & $20.6-43.7$ & 26,910 & $13.85^{* * *}$ \\
\hline Video lottery terminals ${ }^{a}$ & 6.2 & $5.4-7.0$ & 266,435 & $21.7^{\mathrm{b}}$ & $14.0-31.9$ & 26,910 & $31.25^{* * *}$ \\
\hline Poker & 5.4 & $4.7-6.2$ & 233,477 & 66.6 & $55.3-76.2$ & 57,799 & $450.35^{* * *}$ \\
\hline Table games & 2.9 & $2.4-3.4$ & 124,581 & $30.8^{\mathrm{b}}$ & $20.4-43.6$ & 26,715 & $141.75^{* * *}$ \\
\hline Sports betting & 3.6 & $3.1-4.3$ & 157,082 & $35.1^{\mathrm{b}}$ & $23.5-48.8$ & 30,494 & $130.8^{* * *}$ \\
\hline Card games & 4.2 & $3.7-4.8$ & 180,625 & $19.5^{\mathrm{b}}$ & $12.3-29.5$ & 16,893 & $44.35^{* * *}$ \\
\hline Skill games & 5.0 & $4.3-5.8$ & 215,629 & $22.4^{\mathrm{b}}$ & $13.4-35.1$ & 19,470 & $33.38^{* * *}$ \\
\hline \multicolumn{8}{|l|}{ Annual frequency } \\
\hline Less than monthly & 31.9 & $30.6-33.2$ & $1,359,759$ & $7.3^{\mathrm{b}}$ & $3.2-15.8$ & 6,194 & $56.78^{* * *}$ \\
\hline Monthly but not weekly & 28.8 & $27.5-30.1$ & $1,227,168$ & $30.4^{\mathrm{b}}$ & $19.9-43.4$ & 25,662 & \\
\hline Weekly but not daily & 38.3 & $37.0-39.7$ & $1,634,502$ & 43.1 & $31.6-55.4$ & 36,409 & \\
\hline Daily and more & 1.0 & $0.8-1.3$ & 43,591 & $19.2^{\mathrm{b}}$ & $11.1-31.2$ & 16,238 & \\
\hline \multicolumn{8}{|l|}{ Annual spending } \\
\hline 0 to $\$ 100$ & 43.7 & $42.3-45.2$ & $1,820,939$ & $11.8^{\mathrm{b}}$ & $6.3-20.9$ & 9,898 & $52.76^{* * *}$ \\
\hline$\$ 101$ to $\$ 500$ & 35.5 & $34.2-36.9$ & $1,478,122$ & $20.9^{\mathrm{b}}$ & $12.2-33.5$ & 17,609 & \\
\hline$\$ 501$ to $\$ 1,000$ & 10.6 & $9.8-11.5$ & 440,201 & $13.5^{\mathrm{b}}$ & $7.9-22.1$ & 11,381 & \\
\hline$\$ 1,001$ to $\$ 5,000$ & 8.8 & $8.0-9.6$ & 364,873 & $32.3^{\mathrm{b}}$ & $21.5-45.4$ & 27,221 & \\
\hline$\$ 5,001+$ & 1.4 & $1.1-1.8$ & 58,775 & $21.5^{\mathrm{b}}$ & $13.0-33.4$ & 18,079 & \\
\hline \multicolumn{8}{|c|}{ Average play time per session } \\
\hline Less than 1 hour & 20.6 & $18.1-23.3$ & 228,503 & c & $0.9-10.6$ & 2,196 & $5.5^{* *}$ \\
\hline Between 1 and 3 hours & 44.6 & $41.7-47.5$ & 494,896 & $50.4^{\mathrm{b}}$ & $36.5-64.3$ & 35,103 & \\
\hline 3 hours + & 34.8 & $32.1-37.6$ & 385,823 & 46.4 & $32.7-60.7$ & 32,309 & \\
\hline \multicolumn{8}{|l|}{ Gamblers profile } \\
\hline Nonproblem gamblers & 94.4 & $93.7-95.0$ & $4,075,595$ & 63.1 & $50.9-73.9$ & 54,776 & $48.94^{* * *}$ \\
\hline Low-risk gamblers & 3.0 & $2.5-3.5$ & 129,076 & $25.9^{\mathrm{b}}$ & $16.6-38.0$ & 22,472 & \\
\hline Moderate-risk gamblers & 1.8 & $1.4-2.2$ & 77,235 & $4.9^{\mathrm{b}}$ & $2.3-10.3$ & 4,282 & \\
\hline Problem gamblers & 0.8 & $0.6-1.2$ & 35,624 & c & $2.2-15.7$ & 5,275 & \\
\hline
\end{tabular}

${ }^{a}$ Differences were nonsignificant when exclusive lottery players had been removed from the analysis.

${ }^{\mathrm{b}}$ Interpret with caution.

${ }^{c}$ Result nonpublishable.

${ }^{*} p \leq 0.05 ;{ }^{* *} p \leq 0.01 ;{ }^{* * *} p \leq 0.001$. 
10 was used to calculate all estimates and 95\% confidence intervals (CIs), and significant differences were determined from nonoverlapping $95 \%$ CIs. ${ }^{13}$ Coefficients of variation $(\mathrm{CV})$ were also used to evaluate estimate precision. Where the $\mathrm{CV}$ is between 16.6 percent and 33 percent, a dagger symbol indicates that the result should be interpreted with caution. Where the $\mathrm{CV}$ is greater than 33 percent, the result is considered imprecise and has not been disclosed.

\section{Results}

\section{Sociodemographic profile}

Of the total sample $(n=8,456), 8,363$ respondents were offline gamblers who never played online, whereas 111 players (1.97 percent; 95\% CI 1.54-2.50) had bet online at least once during the previous 12 months. It is noteworthy that 92.8 percent $(n=103)$ of online gamblers reported that they also play offline.

Results presented in Table 1 indicate that, compared with offline gamblers, online gamblers were more likely to be male and fall into one of the younger age categories. The greatest proportion of online gamblers was found among 25to 34 -year-olds, with more than 83 percent of online gamblers falling under the age of 45 . Conversely, the largest proportion of offline gamblers was found in the 45- to 54year-old age category. With regard to marital status, the greatest proportion of online gamblers was found among single and cohabiting individuals, whereas the largest proportion of offline gamblers was found among married individuals. For both online and offline gamblers, those working full time were the most likely to report gambling during the last year. Students were the second largest category of online gamblers, whereas retirees were the second largest category of offline gamblers. Level of education, income level, and region were not significantly related to the form of gambling (online/offline).

\section{Game-play patterns}

Compared with offline gamblers, online gamblers were more likely to report all types of gambling activities except for lottery, which was more likely to be reported by offline gamblers (Table 2). Analyses also revealed that online gamblers bet more frequently than offline gamblers, with nearly 60 percent betting at least weekly. By contrast, more than 60 percent of offline gamblers played less than weekly. Moreover, the largest proportion of online gamblers reported spending between $\$ 1,001$ and $\$ 5,000$ annually, whereas the greatest proportion of offline gamblers reported spending less than $\$ 100$ annually on gambling. Online gamblers also reported spending more time per gambling occasion compared with offline gamblers. When they played, 96 percent of online gamblers reported spending at least 1 hour gambling compared with 79 percent of offline gamblers. Finally, online gamblers were significantly more likely to report a higher score on the CPGI than offline gamblers.

\section{Level of addictive behaviors}

The results presented in Table 3 indicate that the form of gambling was not related to tobacco use, but gambling form was significantly related to alcohol and cannabis use. Overall, online gamblers were more likely to report a higher frequency of alcohol consumption. More than 50 percent of online gamblers reported drinking on a weekly basis, and the greatest proportion reported drinking two to three times a week. Conversely, the greatest proportion of offline gamblers

Table 3. Comparison of Offline and Online Gamblers on Addictive Behaviors

\begin{tabular}{|c|c|c|c|c|c|c|c|}
\hline & \multicolumn{3}{|c|}{ Offline gamblers $(\mathrm{n}=8,456)$} & \multicolumn{3}{|c|}{ Online gamblers $(\mathrm{n}=111)$} & \multirow[b]{2}{*}{$\chi^{2}$} \\
\hline & Percent & $95 \% C I$ & Pop. Est. & Percent & $95 \% C I$ & Pop. Est. & \\
\hline \multicolumn{8}{|l|}{ Tobacco use } \\
\hline Daily smoker & 19.6 & $18.6-20.7$ & 847,553 & $26.1^{\mathrm{a}}$ & $17.3-37.3$ & 22,637 & 2.1 \\
\hline Occasional smoker & 4.9 & $4.3-5.7$ & 212,480 & $\mathrm{~b}$ & $3.7-20.5$ & 7,863 & \\
\hline Former smoker/nonsmoker & 75.5 & $74.3-76.6$ & $3,259,303$ & $64.9^{\mathrm{a}}$ & $52.7-75.4$ & 56,304 & \\
\hline \multicolumn{8}{|l|}{ Alcohol consumption } \\
\hline Do not use & 12.4 & $11.5-13.3$ & 533,625 & $7.7^{\mathrm{a}}$ & $3.1-17.8$ & 6,708 & $4^{* *}$ \\
\hline Less than monthly & 22.9 & $21.8-24.1$ & 988,121 & $12.3^{\mathrm{a}}$ & $6.8-21.2$ & 10,637 & \\
\hline Monthly but not weekly & 29.8 & $28.5-31.1$ & $1,285,791$ & $24.5^{\mathrm{a}}$ & $16.7-34.5$ & 21,277 & \\
\hline Two to three times per week & 23.3 & $22.1-24.5$ & $1,006,247$ & $30.8^{\mathrm{a}}$ & $20.6-43.4$ & 26,771 & \\
\hline Four times per week and more & 11.6 & $10.7-12.5$ & 500,198 & $24.7^{\mathrm{a}}$ & $14.7-38.3$ & 21,411 & \\
\hline \multicolumn{8}{|l|}{ AUDIT score } \\
\hline 0 to 7 & 88.2 & $87.2-89.2$ & $3,816,015$ & 63.1 & $49.8-74.7$ & 54,793 & $19.5^{* * *}$ \\
\hline 8 to 10 & 7.1 & $6.4-8.0$ & 308,451 & $15.6^{\mathrm{a}}$ & $8.8-26.0$ & 13,509 & \\
\hline $11+$ & 4.6 & $4.0-5.3$ & 200,078 & $21.3^{\mathrm{a}}$ & $11.4-36.3$ & 18,503 & \\
\hline \multicolumn{8}{|l|}{ Cannabis consumption } \\
\hline Do not use & 88.7 & $87.7-89.7$ & $3,831,695$ & 67.1 & $54.7-77.4$ & 57,449 & $19.05^{* * *}$ \\
\hline Less than monthly & 7.2 & $6.4-8.1$ & 309,680 & $18.2^{\mathrm{a}}$ & $10.7-29.1$ & 15,581 & \\
\hline Monthly but not weekly & 1.4 & $1.1-1.7$ & 58,121 & $11.4^{\mathrm{a}}$ & $5.2-23.2$ & 9,772 & \\
\hline Two to three times per week & 1.1 & $0.8-1.4$ & 45,361 & b & $0.8-7.9$ & 2,199 & \\
\hline Four times per week and more & 1.7 & $1.3-2.2$ & 73,436 & $\mathrm{~b}$ & $0.2-3.3$ & 660 & \\
\hline
\end{tabular}

${ }^{\mathrm{a}}$ Interpret with caution.

${ }^{*} p \leq 0.05 ;{ }^{* *} p \leq 0.01 ;{ }^{* * *} p \leq 0.001$.

AUDIT, Alcohol Use Diagnostic Identification Test. 
was found among those who drink less than weekly. Moreover, the proportion of online gamblers who were identified as problem drinkers on the AUDIT (21.3 percent) was significantly higher than the proportion observed among offline gamblers (4.6 percent). Finally, compared with offline gamblers, a significantly greater proportion of online gamblers reported using cannabis during the last 12 months (32.9 percent vs. 11.3 percent for offline gamblers).

Given that a large majority of offline gamblers (70 percent) were exclusively lottery players, we ran all the analyses after removing this particular group from the sample. All the results remained unchanged except three: (a) higher participation in lottery playing among offline gamblers became nonsignificant (b) higher prevalence of betting on slot machines among online gamblers became nonsignificant (c) higher prevalence of betting on video lottery terminals among online gamblers became nonsignificant.

\section{Discussion}

The analyses presented in this article show an unequal distribution of online gambling in the population. In accordance with other studies, ${ }^{14-16}$ we found a disproportionate number of men, young people, and students among online gamblers.

There was an association between gambling form and game-play patterns. We found an overrepresentation of poker players among online gamblers. Our findings also suggest that gambling behaviors tend to be more excessive on the Internet. Frequency of play, spending, and gambling time are significantly greater among online gamblers. We, like others, ${ }^{14-16}$ observed that gambling problems are more severe among online gamblers.

Finally, our results indicate higher co-occurrence of other risky behaviors, namely alcohol and cannabis use, with online gambling. This result should not be surprising. From a psychological perspective, the same vulnerability factors that contribute to gambling may contribute to other risk-taking behaviors. From a lifestyle perspective, collective life conditions largely determine a series of health-related behaviors through combinations of chances and choices. ${ }^{17,18}$ Cooccurrence ought to be thought of as the result of multiple common biological, social, and environmental conditions. ${ }^{19}$

The present findings alone cannot be used as evidence that those who gamble online are more at risk for gamblingrelated problems. The cross-sectional nature of this study makes it impossible to infer directionality in the association between the Internet setting for gambling and the occurrence or exacerbation of gambling-related problems. We cannot determine, for example, whether gambling on the Internet creates problems in and of itself, or whether those who are already experiencing problems are more likely to be enticed to gamble on the Internet. Only a longitudinal research design would permit the careful examination of gambling trajectories and associated problems among online gamblers. Likewise, observed associations between individual characteristics (the set), environmental conditions (the online setting), and the object of addiction (mostly poker gambling) lead us to conclude that future research will need to expand to more comprehensive multilevel models. Research designs combining longitudinal data collection and multilevel analyses could provide more insight into the causal mechanisms associated with online gambling.

\section{Acknowledgments}

The authors are very thankful to Elyse Picard and Lina Mihaylova for their valuable contribution to this article.

This study was conducted while Sylvia Kairouz and Louise Nadeau were supported by the Fonds québécois de la recherché sur la société et la culture (FQRSC) operation grant.

Source of work: Portrait of Gambling in Québec survey 2008 (ENHJEU-QUÉBEC).

\section{Disclosure Statement}

No competing financial interests exist.

\section{References}

1. Christiansen Capital Advisors (2004). CCA's Global Internet Gambling Revenue Estimates and Projections (2001-2010, $\$ M$, US). http://www.ccai.com/primary\%20navigation/ online $\% 20$ data $\% 20$ store/internet_gambling_data.htm. (accessed November 17, 2011).

2. La Presse Canadienne. (2010) La santé publique s'inquiète des problèmes associés aux jeux en ligne: UN moratoire est demandé sur le projet de Loto-Québec. Le Devoir. February 18, 2010. www.ledevoir.com/politique/quebec/283354/ la-sante-publique-s-inquiete-des-problemes-associes-aux-jeuxen-ligne (accessed February 15, 2011).

3. Griffiths M. Internet gambling: issues, concerns, and recommendations. CyberPsychology \& Behavior 2003; 6: 557-568.

4. Griffiths M, Parke A, Wood R, et al. Internet Gambling: an overview of psychosocial impacts. UNLV Gaming Research and Review Journal 2006; 10:27-39.

5. Griffiths M, Parke J. The Social impact of Internet gambling. Social Science Computer Review 2002; 20:312-320.

6. Wood RT, Williams RJ. Problem gambling on the internet: implications for Internet gambling policy in North America. New Media \& Society 2007; 9:520-542.

7. Griffiths M, Wardle H, Orford J, et al. Sociodemographic correlates of Internet gambling: findings from the 2007 British Gambling Prevalence Survey. CyberPsychology \& Behavior 2009; 12:199-202.

8. Ladd G, Petry N. Disordered gambling among universitybased medical and dental patients: a focus on Internet gambling. Psychology of Addictive Behaviours 2002; 16: 76-79.

9. Cole T, Barrett D, Griffiths M. Social facilitation in online and offline gambling: a pilot study. International Journal of Mental Health and Addiction 2010; 8:1-8.

10. Ferris J, Wynne HJ. (2001) The Canadian problem gambling index: final report. Report to the Canadian Inter-Provincial Committee. Ottawa, Canada: Canadian Centre on Substance Abuse.

11. Babor TF, Higgins-Biddle JC, Saunders JB, et al. (2001) A U D I T-The alcohol use disorders identification test. Geneva: World Health Organization.

12. Saunders JB, Aasland OG, Babor TF, et al. Development of the alcohol use disorders identification test (AUDIT): WHO Collaborative Project on Early Detection of Persons with Harmful Alcohol Consumption-II. Addiction 1993; 88:791-804.

13. StataCorp. (2007) Stata statistical software. 10th ed. College Station: StataCorp LP.

14. Lee G, Pearce G. Profiling online gamblers: an exploratory study. International Journal of Business Research 2007; 7:109-118. 
15. Wood RT, Williams RJ. (2009) Internet gambling: prevalence, patterns, problems, and policy options. Final Report prepared for the Ontario Problem Gambling Research Centre, Guelph, Ontario, Canada.

16. Woodruff C, Gregory S. Profile of Internet gamblers: betting on the future. UNLV Gaming Research \& Review Journal 2005; 9:1-14.

17. Cockerham WC, Rutten A, Abel T. Conceptualizing contemporary health lifestyles: moving beyond Weber. The Sociological Quarterly 1997; 38:321-342.

18. Frohlich KL, Corin E, Potvin L. A theoretical proposal for the relationship between context and disease. Sociology of Health \& Illness 2001; 23:776-797.
19. Griffiths, M. A "components" model of addiction within a biopsychosocial framework. Journal of Substance Use 2005; 10:191-197.

Address correspondence to: Dr. Sylvia Kairouz Department of Sociology and Anthropology Concordia University 1455 de Maisonneuve Blvd. West, Montreal, Quebec, H3G 1M8 Canada

E-mail: skairouz@alcor.concordia.ca 